\title{
ANÁLISE PRAXIOLÓGICA DO VOLEIBOL SENTADO: ELEMENTOS PARA O PROCESSO DE ENSINO-APRENDIZAGEM A PARTIR DA LÓGICA INTERNA
}

\author{
Felipe Menezes Fagundes \\ Universidade Federal de Santa Maria, Santa Maria, Rio Grande do Sul, Brasil. \\ João Francisco Magno Ribas \\ Universidade Federal de Santa Maria, Santa Maria, Rio Grande do Sul, Brasil.
}

\begin{abstract}
Resumo
Este ensaio objetiva identificar os elementos relevantes da lógica interna do voleibol sentado para o processo de ensino-aprendizagem. A partir de uma pesquisa teórica e de uma análise praxiológica, evidenciaram-se características do voleibol sentado, com base em artigos científicos sobre o tema e pela ferramenta de análise Universais, da Praxiologia Motriz. Como resultados, salientam-se o protagonismo das interações motrizes para a organização do jogo e a atuação dos jogadores, a necessidade de conhecer as possibilidades de ação dos papéis e subpapéis e a pertinência da leitura de jogo e da interpretação dos comportamentos motores. Por fim, sintetizaram-se esses conhecimentos referentes à lógica interna do voleibol sentado para o processo de ensino-aprendizagem para além do tecnicismo.
\end{abstract}

Palavras-chave: Voleibol sentado. Esporte. Praxiologia Motriz. Ensino.

\section{PRAXIOLOGICAL ANALYSIS OF SITTING VOLLEYBALL: ELEMENTS FOR THE TEACHING-LEARNING PROCESS FROM INTERNAL LOGIC}

\begin{abstract}
This essay aims to identify the relevant elements of the internal logic of Sitting Volleyball for the teaching-learning process. From a theoretical research and a praxiological analysis, characteristics of the Seated Volleyball were evidenced, based on scientific articles on the theme and by the Universal analysis tool of the Motor Praxiology. As a result, it is important to highlight the role motor interactions for game organization and player performance, the need to know the possibilities of action of roles and subroles, game reading's pertinence and motor behavior's interpretation. Finally, this knowledge was synthesized referring to the Sitting Volleyball's internal logic for the teaching-learning process beyond technicality.

Keywords: Sitting Volleyball. Sport. Motor Praxiology. Teaching.

\section{ANÁLISE PRAXIOLÓGICO DEL VOLEIBOL SENTADO: ELEMENTOS PARA EL PROCESO DE ENSEÑANZA-APRENDIZAJE A PARTIR DE LA LÓGICA INTERNA}

\section{Resumen}

Este ensayo tiene el objetivo de identificar los elementos importantes de la lógica interna del Voleibol Sentado para el proceso de enseñanza-aprendizaje. A partir de una investigación teórica y de un análisis praxeológico, se demostraron características del Voleibol Sentado, con 
base en artículos científicos sobre el tema y en la herramienta de análisis Universales de la Praxeología Motriz. Como resultados, se destacan el protagonismo de las interacciones motrices para organizar el juego y la actuación de los jugadores; la necesidad de conocer las posibilidades de acción de los roles y subroles; y la pertinencia de la lectura del juego y de la interpretación de los comportamientos motores. Finalmente, se sintetizaron los conocimientos referentes a la lógica interna del Voleibol Sentado para el proceso de enseñanza-aprendizaje más allá del tecnicismo.

Palabras clave: Voleibol Sentado. Deporte. Praxeología Motriz. Enseñanza.

\section{Introdução}

Os esportes adaptados vêm ganhando destaque no Brasil. Haraichi et al (2016) credencia esse crescimento às conquistas obtidas pelo paradesporto brasileiro nos Jogos Paralimpícos de Londres 2012 - sétimo lugar no quadro de medalhas - e pela liderança consecutiva de três Jogos Para-panamericanos (2007, 2011 e 2015), a principal competição continental. Marques et al. (2009) apontam para a pluralidade da manifestação dos esportes adaptados em diversas âmbitos sociais, diretamente vinculados aos anseios, às metas e às características dos praticantes em questão.

Um exemplo que ilustra essa assertiva é o voleibol sentado, manifestado como reabilitação física, ferramenta de inclusão social, bem como esporte de alto rendimento, concretizando-se como prática popularmente difundida. Esse paradesporto surgiu na Holanda, em 1956, oriundo da união do sitzball ${ }^{1}$ e do voleibol convencional (em pé), como alternativa de prática para soldados que tiveram amputações ou sofreram lesões no período da Segunda Guerra Mundial (BRITTAIN, 2010 apud CARVALHO; GORLA; ARAÚJO, 2013). Entretanto, só no ano de 1976, nos Jogos Paralimpícos de Toronto, houve a apresentação do voleibol sentado como prática institucionalizada no âmbito mundial, na forma de esporte exibição, sendo incluída como modalidade oficialmente paralímpica na edição seguinte do evento, nas Paralimpíadas de Arhmen, na Holanda, em 1980 (MIRON, 2011).

O voleibol sentado, como esporte institucionalizado, é regulamentado pela World Organization Volleyball for Disabled - WOVD (Organização Mundial de Voleibol para Deficientes), que objetiva desenvolver a modalidade num âmbito mundial. Com esse pressuposto, a WOVD categoriza os atletas de alto nível para que haja uma homogeneidade quanto às características físicas dos jogadores das equipes. Cada tipo de deficiência é alocado em uma das nove classes (A1 à A9), que varia a partir do grau de amputação ou eficiência motora de membros inferiores e/ou superiores (WORLD PARAVOLLEY, 2017). Há outra categoria, denominada Les Autres, que engloba os atletas que apresentam outras deficiências que não a amputação, como paralisia cerebral, lesão medular, distrofia muscular, entre outras (WORLD PARAVOLLEY, 2017).

Em se tratando de um esporte, o voleibol sentado apresenta um corpo de regras fixas, o qual precisa ser seguido fielmente no alto rendimento, mas que pode e deve ser readequado a partir do contexto e dos objetivos de cada processo de ensino-aprendizagem, seja este escolar ou não. Miron (2011, p. 130) é taxativo ao afirmar que "o Voleibol Sentado, desenvolvido com obediência às suas regras e de maneira formal, não é a maneira mais adequada para ser aprendido ou ensinado inicialmente".

\footnotetext{
${ }^{1}$ Jogo tradicional alemão similar ao voleibol sentado, no qual os participantes rebatem a bola, porém sem ter o espaço dividido por uma rede (CARVALHO; GORLA; ARAÚJO, 2013) 
Para Miron e Costa (2013), o voleibol sentado é uma modalidade democrática, sendo sua prática uma possibilidade de coeducação, desde que abordada com um trato pedagógico específico para seu desenvolvimento. Pautado nisso, a atuação dos professores/profissionais de Educação Física que objetivam trabalhar com o voleibol sentado necessita de subsídios para o desenvolvimento de aulas ou sessões de treinamento. Esses elementos precisam estar em consonância com a forma como o esporte se manifesta, das características mais amplas às mais específicas. Galatti et al. (2014), pautados na evolução científica da produção referente a esportes, afirmam que, atualmente, os referenciais metodológicos apontam para uma didática focada na lógica do jogo, valorizando a compreensão tática, a partir de situações-problema nele expressas.

No que se refere à análise do funcionamento das práticas, tem-se a Praxiologia Motriz como uma área de conhecimento que visa sistematizar saberes referentes às práticas motrizes, apresentando-se como uma teoria científica que tem como objetivo estudar a lógica interna dos jogos e dos esportes. Para Parlebas (2001, p. 302), lógica interna é um "sistema de características pertinentes de uma situação motriz e das consequências que implica para a realização da ação motriz correspondente". Assim, a lógica interna conduzirá a forma como os jogadores atuarão no jogo, a partir do estabelecimento de normas quanto às possibilidades de interação com os quatro elementos que compõem o jogo: espaço, demais jogadores, material e tempo. Dessa forma, a lógica interna reflete a dinâmica de funcionamento em um contexto aplicado, em consonância com aquilo que está descrito nas regras do jogo. Quando postas em ação, essas regras materializam um sistema praxiológico, dotado de sentido e que reflete uma dinâmica racional, uma lógica interna que orienta as possibilidades de atuação nas diferentes situações motrizes que um jogador pode vivenciar, elementos primordiais para o ensino esportivo.

Com base na complexidade dessas relações da lógica interna dos esportes, Parlebas (2001) desenvolveu uma ferramenta de análise para identificar essas características, denominada Universais. Segundo o autor, ela constitui-se de "modelos operativos que representam as estruturas básicas do funcionamento de todo jogo esportivo e que contém sua lógica interna" (PARLEBAS, 2001, p. 463). Esses modelos denominam-se Rede de Comunicação Motriz, Rede de Interação de Marca, Sistema de Pontuação, Sistema de Troca de Papéis, Sistema de Troca de Subpapéis, Gestema e Praxema (LAGARDERA; LAVEGA, 2003). Com esse pressuposto, este ensaio objetiva identificar os elementos relevantes da lógica interna do voleibol sentado para o processo de ensino-aprendizagem a partir dos Universais.

\section{Metodologia}

Essa investigação configura-se como uma pesquisa teórica, a qual se dedica "a formular quadros de referência, estudar teorias, burilar conceitos" (DEMO, 1995). Ao considerar o objetivo estabelecido, este estudo apresenta caráter exploratório-propositivo, ao passo que irá caracterizar e sistematizar os elementos inerentes à lógica interna do voleibol sentado para seu processo de ensino-aprendizagem

Para a discussão aqui proposta, também se fez uso de uma revisão de literatura que, segundo Gil (2008, p. 50), "é desenvolvida a partir de material já elaborado, constituído principalmente de livros e artigos científicos". Utilizou-se de artigos científicos que dissertaram sobre voleibol sentado, localizados a partir das palavras-chave "Voleibol Sentado", nos indexadores Scielo, Latindex, Portal de Periódicos da CAPES, Scopus, Lilacs e em busca on-line na ferramenta Google Acadêmico. Para a delimitação do referencial teórico, utilizou-se dos parâmetros propostos por Salvador (1986), os quais são: parâmetro temático, linguístico, cronológico e as principais fontes. Foram considerados estudos em português que 
trataram de apresentar e/ou discutir a dinâmica de funcionamento do voleibol sentado, bem como seu processo de ensino-aprendizagem, selecionados a partir de uma filtragem após a leitura dos resumos dos artigos contemplados na busca, totalizando seis artigos e uma tese. Não se estabeleceu nenhum recorte temporal para a seleção das obras, tendo em vista a escassez de publicações em torno da temática, já apontada em outros estudos como os de Carvalho, Gorla e Araújo (2013), Borges et al. (2016) e Macedo, Mesquita e Silva (2007).

Além disso, ao considerar a utilização dos Universais para a análise praxiológica, este estudo caracteriza-se, como apontam Hernández Moreno e Rodríguez Ribas (2004, p. 66), como uma modelização, que objetiva "capturar uma imagem sobre uma realidade complexa (por exemplo, uma situação ou uma sequência ou aspectos da mesma) de modo que facilite sua compreensão". Esse tipo de pesquisa visa apontar ao pesquisador como se dá a dinâmica de funcionamento de determinada prática, caracterizando essas manifestações a partir de um entendimento estruturalista.

Para condicionar uma melhor organização em relação aos resultados do estudo, serão elucidadas as características de cada modelo dos Universais concomitantemente ao processo de análise da lógica interna do voleibol sentado, à medida que forem abordados nesta investigação. Além disso, uniram-se quatro modelos dos Universais (Papel/Subpapel e Gestema/Praxema) por suas proximidades quanto à análise, com o intuito de articular suas contribuições no processo de ensino-aprendizagem de forma clara. Por fim, optou-se por já indicar as possibilidades didático-pedagógicas à medida que se discute cada modelo dos Universais, no sentido de dar mais unidade ao estudo, e sintetizar os principais elementos evidenciados no fim da discussão.

\section{Resultados e discussão}

Antes de iniciar com o processo de análise da lógica interna do voleibol sentado, mostra-se a necessidade de expor alguns elementos básicos da organização dessa modalidade, condicionando a compreensão das discussões que serão propostas nesta pesquisa. No que se refere ao objetivo motor da prática, o voleibol sentado apresenta a mesma dinâmica do voleibol, uma equipe objetivando fazer com que a bola toque o solo da quadra adversária, tentando evitar que a outra equipe logre êxito nessa tarefa (CARVALHO; GORLA; ARAÚJO, 2013).

Quanto às características da lógica interna, em relação ao espaço de prática, ambas as modalidades são divididas por uma rede, com campos invioláveis, além de não exigirem de seus praticantes nenhum tipo de leitura em relação à incerteza expressa pelo meio, pois ele é padrão. No entanto, as dimensões da quadra foram reduzidas (como expresso na figura a seguir), bem como a altura da rede também foi adaptada em relação ao voleibol convencional, estabelecendo-se por 1,15 metro para o naipe masculino e 1,05 metro para o feminino (MIRON, 2011). 
Figura 1 - Dimensões da quadra de voleibol sentado

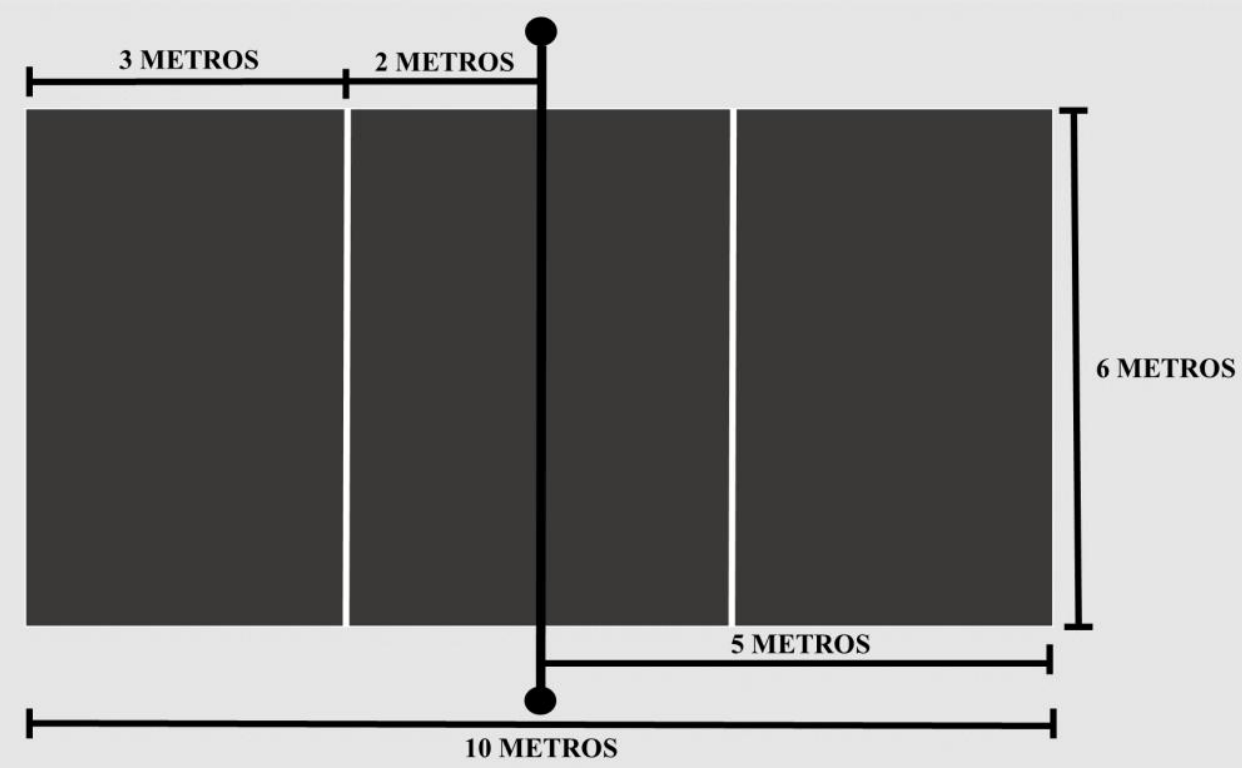

Fonte: Elaborada pelos autores, 2017.

No que tange às possibilidades de atuação com o material, nas duas práticas motrizes só é permitido o uso da habilidade motora de rebater, impossibilitando a retenção e a manipulação da bola (exceto antes do saque), o que remete a constantes e complexas tomadas de decisão em curtos feixes de tempo, como apontam os estudos de Fagundes, Oliveira e Ribas (2015) e Bizzochi (2008). Já quanto às interações com o tempo, tanto o voleibol quanto o voleibol sentado desfrutam da mesma relação temporal no que se refere às possibilidades de interação em sua lógica interna, que se baseiam na dependência de atingir determinada pontuação preestabelecida e não com um limite de tempo fixo, fato que demonstra a pouca pertinência da relação temporal para o voleibol sentado.

Uma importante regra do voleibol sentado merece ser destacada, a qual condiciona diretamente a forma de atuação dos jogadores. Diferentemente do voleibol, em que os jogadores podem desprender-se do solo e atacar em suspensão, no voleibol sentado, em nenhum momento, os jogadores podem tocar a bola sem estar com alguma parte do corpo (entre os ombros e as nádegas) em contato com o solo (CARVALHO; GORLA; ARAÚJO, 2013). Essa falta denomina-se lifting (traduzido do inglês: elevação) e concede um ponto direto ao adversário quando um jogador a comete.

Seguindo as possibilidades de interação motriz a partir da lógica interna, quando se citam as relações estabelecidas entre jogadores, já se configuram análises que se articulam com o primeiro modelo dos Universais, a Rede de Comunicação Motriz, expressa pelas interações de cooperação e oposição. Considerando o voleibol sentado, percebe-se que os jogadores estabelecem as relações de cooperação e de oposição simultaneamente ao interagirem no contexto do jogo. A cooperação constitui-se a partir dos processos de facilitação das ações e das leituras dos companheiros no que se refere aos comportamentos motores dos participantes (PARLEBAS, 2001). Por outro lado, a oposição objetiva, a todo momento, dificultar as ações e as leituras de jogo dos adversários (PARLEBAS, 2001). Essas características tornam a Rede de Comunicação Motriz do voleibol sentado do tipo exclusiva e estável, pois são conhecidas e imutáveis as interações motrizes estabelecidas e sempre será evidente quem são companheiros e adversários durante o jogo (LAGARDERA; LAVEGA, 2003). 
Ribas (2014), ao articular os conceitos da Praxiologia Motriz com o voleibol, divide a modalidade em momentos de jogo e evidencia as interações motrizes que se estabelecem entre eles. Em um movimento similar, sistematizou-se a figura abaixo, que sintetiza as interações motrizes estabelecidas entre as etapas do jogo de voleibol sentado, apontando as características que se apresentam a partir dessa organização da lógica interna. Vale ressaltar que os momentos denominados contra-ataque representam a mesma dinâmica estabelecida entre recepção, levantamento e ataque, os quais dão forma à disputa do ponto no decorrer do jogo.

Figura 2 - Interações motrizes estabelecidas entre os momentos do voleibol sentado

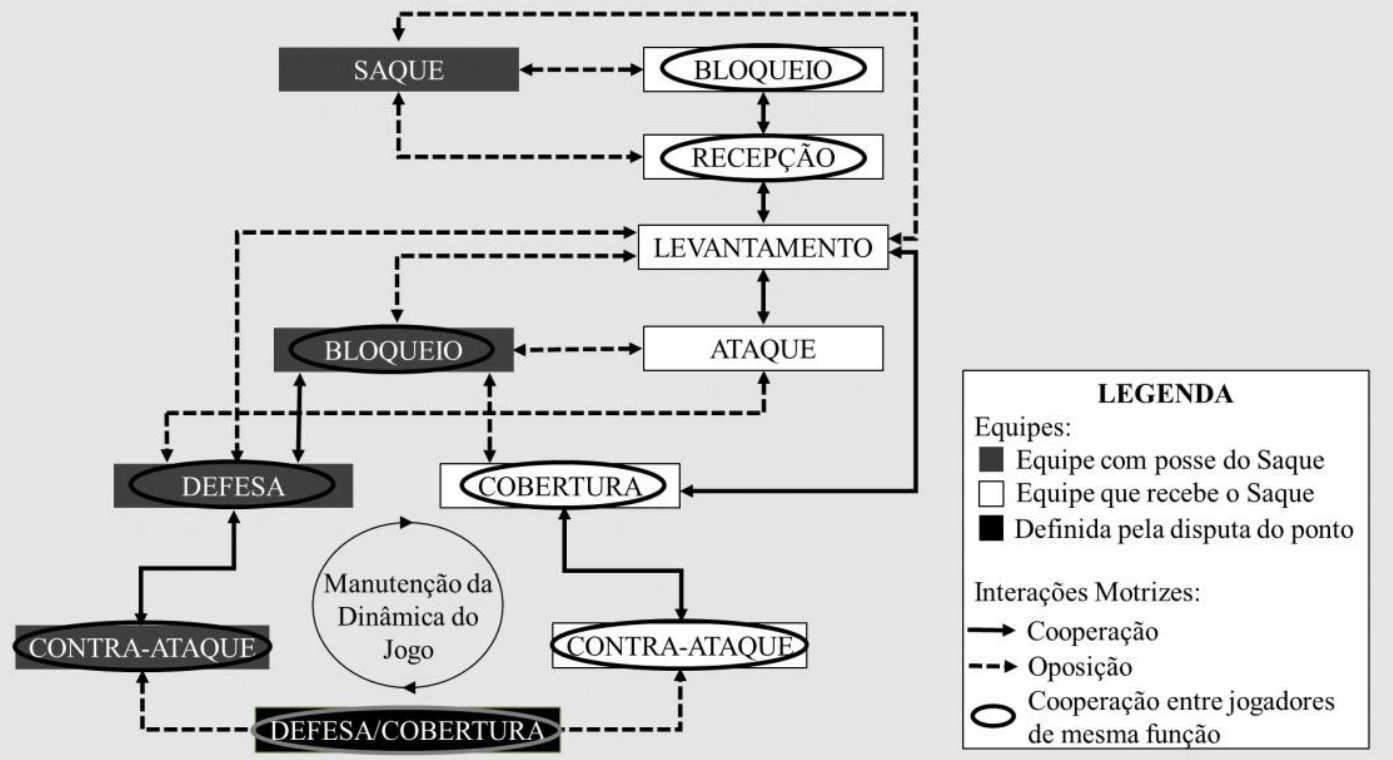

Fonte: Elaborada pelos autores, 2017.

Em relação à proposta apresentada por Ribas (2014) sobre o voleibol, as interações estabelecidas entre os momentos do voleibol sentado evidenciam algumas distinções que merecem destaque. Em virtude da possibilidade de bloqueio do saque, estabelecem-se novas configurações no que tange às interações motrizes, acarretando interferências substancias no contexto do jogo. Nesse sentido, o sacador precisa considerar, além da recepção e do levantamento do adversário, a organização do bloqueio, a qual buscará impedir ou dificultar essa ação, o que remete à oposição. Além disso, a recepção adversária deverá estabelecer um processo cooperativo com o bloqueio, no intuito de reduzir os espaços da quadra e condicionar um bom passe para a organização ofensiva.

Em uma primeira impressão, talvez esses conhecimentos não denotem considerações relevantes para o processo de ensino-aprendizagem. No entanto, conhecer as interações motrizes estabelecidas entre os momentos do voleibol sentado é substancial para um bom desenvolvimento dessa - e qualquer - prática motriz, ao apontar os elementos cruciais a serem considerados nas atividades didáticas propostas. As interações motrizes devem permear todo o processo, guiando as formas de atuação dos jogadores a partir das características específicas de cada momento do jogo (RIBAS, 2014).

Ainda se referindo às interações motrizes do jogo, avança-se no processo da análise praxiológica, ao utilizar-se do modelo Rede de Interação de Marca, o qual se detém a conhecer qual interação motriz deve ser estabelecida para vencer um jogo (LAGARDERA; LAVEGA, 2003). Parlebas (2001, p. 391) conceitua esse modelo como "um subgráfico da Rede de Comunicação Motriz, já que estas tão somente refletem as interações de marca que 
contam para a pontuação". Com essa concepção, constata-se que, para pontuar no voleibol sentado, é necessário opor-se aos adversários, já que só se avança no placar ao pôr a bola no chão da quadra da outra equipe ou por meio dos erros do oponente, caracterizando uma Rede de Interação de Marca antagônica, pautada na oposição. Com isso, as estruturas didáticas das aulas/treinamentos precisam remeter a essa característica opositiva na conquista do ponto, principalmente se a escolha metodológica do professor/treinador for o ensino esportivo por jogos condicionados (GARGANTA, 1998).

Entretanto, ressalva-se que essa característica não desvaloriza os processos cooperativos no voleibol sentado, pelo contrário, os dota de relevância, já que, para a organização - ofensiva ou defensiva - de uma equipe, os processos cooperativos são extremamente necessários. Para opor-se com qualidade, torna-se vital que a cooperação ocorra adequadamente na construção da jogada. Além disso, vale ressaltar que falhas na cooperação que acarretem erros gerarão pontos para o adversário, o que interferirá diretamente no placar e, obviamente, no resultado do jogo. Esses elementos cooperativos são fundamentais para o processo de ensino-aprendizagem, tanto para a excelência das ações quanto para aspectos pedagógicos, no que se refere à importância do jogo coletivo e da participação de todos no processo formativo.

Tão relevante quanto saber que tipo de interação é necessário estabelecer para vencer o jogo, uma análise praxiológica precisa considerar a forma como se registram os êxitos e as falhas dos jogadores, a partir do Sistema de Pontuação (LAGARDERA; LAVEGA, 2003). Parlebas (2001, p. 421) configura esse modelo como "rede de acertos, vitórias ou pontos conseguidos pelos jogadores ou pelas equipes de um jogo desportivo [...]". Tendo como parâmetro o voleibol sentado, percebe-se que essa prática adota um sistema com pontuaçãolimite, caracterizado por não possibilitar um controle temporal, pois sua finalização está à mercê da pontuação das equipes.

Bem como o já conhecido sistema de rali do voleibol, o voleibol sentado prescreve que, para vencer o jogo, é necessário obter 25 acertos em, no mínimo, três sets. Caso ambas as equipes vençam dois sets, realiza-se o chamado tie-break, set de menor duração - até 15 pontos -, o qual definirá o vencedor da partida. Ressalva-se que, em qualquer um dos sets (inclusive o tie-break), a equipe precisa lograr uma diferença de, pelo menos, dois pontos, não existindo um limite de pontuação até alguma equipe estabelecer essa diferença.

Quanto às contribuições que a análise do Sistema de Pontuação apresenta ao processo de ensino-aprendizagem do voleibol sentado, uma estratégia pedagógica interessante é valorar mais pontos para determinadas ações ou combinações de jogadas específicas no jogo, em concordância ao objetivo estabelecido com a atividade. Um exemplo simples: considerandose uma aula que visa desenvolver o bloqueio, propõe-se um jogo reduzido, em que toda vez que uma disputa de ponto for finalizada com um bloqueio serão contabilizados dois pontos. Essa alteração da regra, com relação direta com o Sistema de Pontuação, instigará os jogadores a priorizarem a realização do bloqueio, condicionando sua execução e, consequentemente, seu desenvolvimento de forma mais significativa no jogo.

Outro elemento-chave para a compreensão da dinâmica de funcionamento de uma prática motriz faz menção às possibilidades de atuação que os jogadores ostentam. Parlebas (2001), embasado nessa premissa, elaborou o Sistema de Troca de Papéis e Subpapéis, o modelo dos Universais que visa compreender as funções dos jogadores, ao se inserirem em uma prática motriz, a partir das possibilidades evidenciadas nas regras do jogo. Como já elucidado, neste estudo optou-se por aglutinar alguns dos modelos dos Universais para melhor condicionar sua compreensão na lógica interna do voleibol sentado, como no caso dos papéis e subpapéis. Assim, entende-se papel como um "conjunto de direitos e proibições prescritas a um jogador pelas regras do jogo esportivo considerado, prescrições essas que definem o campo das ações motrizes autorizadas" (PARLEBAS, 2001, p. 399). Já os subpapéis são 
entendidos como "sequência ludomotriz de um jogador considerada como unidade comportamental básica de funcionamento estratégico de um jogo esportivo" (PARLEBAS, 2001, p. 430). Em outras palavras, os papéis configuram as possibilidades de atuação que a regra concede aos jogadores que os assumem, os quais resultarão em subpapéis especificamente categorizados a partir do comportamento motor estabelecido.

Nesse sentido, o voleibol sentado apresenta quatro papéis específicos, ao considerar as possibilidades de atuação expressas nas regras, os quais são: atacante, defensor, sacador e líbero. ${ }^{2}$ Cada um desses papéis acarreta possibilidades de atuação singulares, as quais se materializarão em subpapéis específicos. A figura abaixo sintetiza os papéis de atacantes, defensores e sacador, bem como suas áreas de atuação e os subpapéis consequentes.

Figura 3 - Papéis e os respectivos subpapéis do voleibol sentado

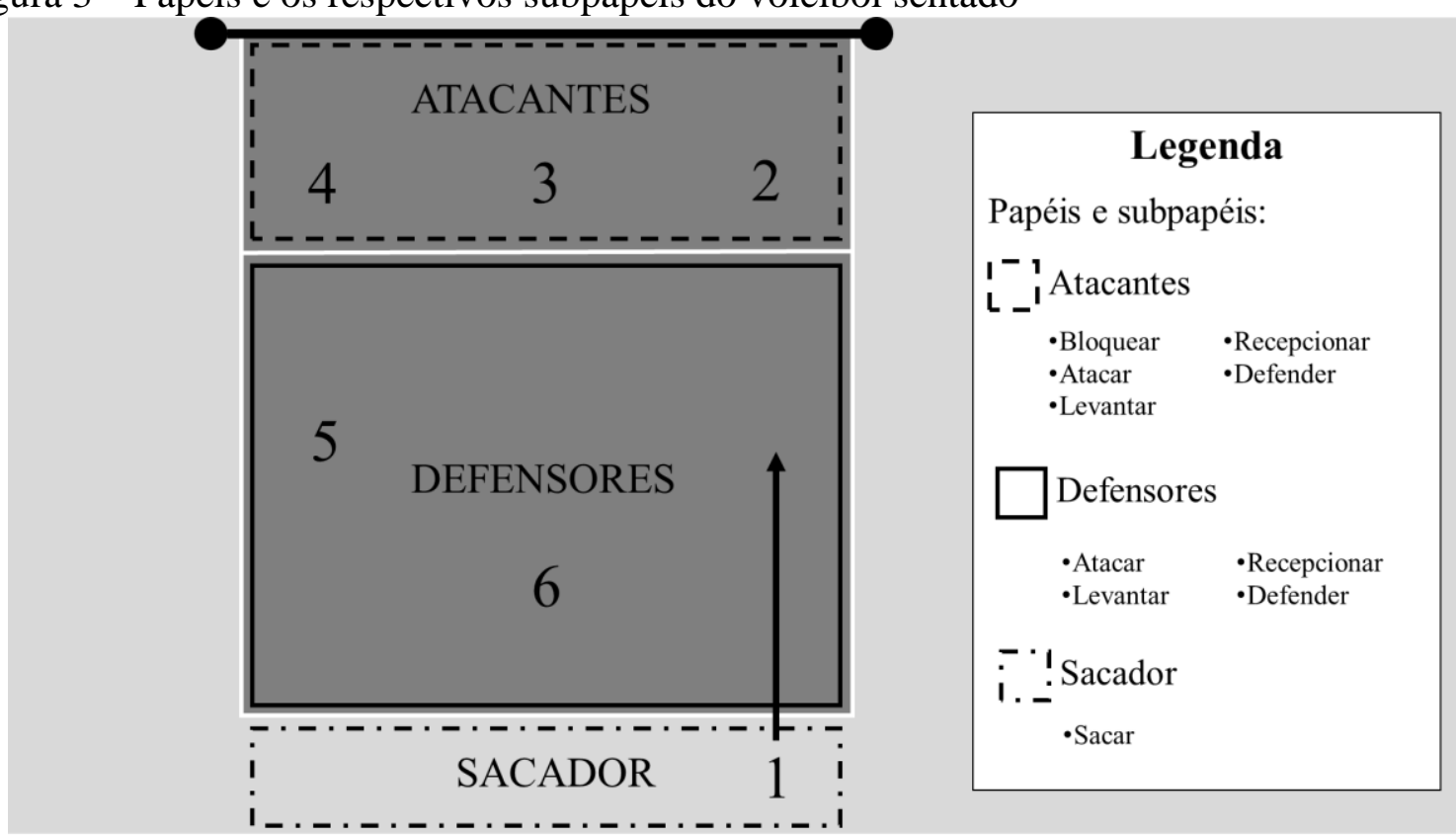

Fonte: Elaborada pelos autores, 2017.

Com esse panorama, percebe-se que os papéis estão intimamente ligados à posição que o jogador ocupa na rotação, que pode ser na zona de ataque (posições 4,3 e 2 ) ou na zona de defesa (1, 6 e 5) e a troca de papéis se dá a partir da manutenção da posse do saque (sacador), após sua execução (sacador para defensor) ou pela troca de zona por meio da rotação (defensor para atacante e vice-versa). Quando o jogador está na zona de ataque, com o papel de atacante, todos os subpapéis lhe são concedidos, exceto sacar. Já quando ele se encontra na zona de defesa, dois podem ser seus papéis, sacador ou defensor. Quando o jogador é o sacador, só lhe é permitido sacar e, logo após realizar o saque, se torna um defensor, podendo realizar qualquer subpapel, exceto bloquear. Salienta-se que só é permitido ao defensor realizar um ataque se este for executado antes da linha dos três metros, com base no posicionamento das nádegas, como previsto em regra.

Nesse sentido, é necessário esclarecer que o papel exercido por um jogador difere da sua função estabelecida no jogo. O papel está vinculado à posição que o jogador ocupa na rotação, o que concede direitos e proibições especificamente relacionados à regra do jogo, enquanto a função é delimitada com base no sistema de organização estratégica adotado pela

\footnotetext{
${ }^{2}$ Salienta-se que este estudo não discutiu as possibilidades do papel do líbero, em virtude de sua especificidade no contexto do jogo e de existir um conjunto de regras específico para esse jogador, o que remeteria a um aprofundamento que não se enquadra ao objetivo desta investigação.
} 
equipe. Para ilustrar isso, cita-se a função do levantador, que tem a tarefa de organizar as ações ofensivas da equipe. Sempre que possível, será o levantador quem optará qual jogador acionar durante o levantamento. Contudo, essa demanda não é exclusiva dele, qualquer outro jogador pode realizar essa ação caso necessário, pois a regra não determina que apenas o levantador tenha que realizá-la. Entretanto, quando o jogador está assumindo o papel de defensor, independentemente de sua função, ele nunca poderá bloquear, pois quem é defensor não contempla esse subpapel, como explicitado na regra, assim como estará impedido de sacar, subpapel restrito a quem exerce o papel de sacador.

Para o processo de ensino-aprendizagem, é evidente que o professor precisa atentar para as possibilidades de atuação expressas a partir dos diferentes papéis do voleibol sentado. Carvalho, Gorla e Araújo (2013) e Miron e Costa (2013) expõem a relevância de vivenciar todas as posições, o que amplifica o leque de experiências para uma futura especialização em determinada função do jogo. Com esse panorama, o professor deve estabelecer situações em que os alunos compreendam as características de cada papel, bem como os subpapéis próprios em cada momento, a partir de atividades que condicionem essas possibilidades de atuação. Essa problematização é extremamente necessária para o processo de ensino-aprendizagem, ao estabelecer as primeiras considerações quanto à função que cada aluno tem para a organização do jogo, já almejando elementos que poderão ser tematizados na sequência do processo, no que tange ao desenvolvimento dos aspectos estratégicos do voleibol sentado.

Além de conhecer quais são as possibilidades dos papéis e seus subpapéis, um bom jogador conhece o "idioma do voleibol sentado". Isso quer dizer que, assim como toda prática motriz, o voleibol sentado tem uma linguagem própria, a qual não é expressa pela comunicação verbal, mas sim pela semiotricidade (LAGARDERA; LAVEGA, 2003). Para Parlebas (2001, p. 406), semiotricidade é a "natureza e campo das situações motrizes, consideradas desde o ponto de vista da aplicação de sistemas de sinais, associados diretamente à conduta motriz dos participantes". Isso significa que, nas práticas sociomotrizes, a comunicação práxica suscita uma troca de mensagens entre os participantes, por meio de interpretações das ações motrizes como emissoras de informação, dotadas de uma simbologia comum, enriquecidas de sentido e passíveis de leitura para quem atua no jogo. Nesse sentido, dois modelos dos Universais mostram-se cabais para analisar como esse tipo de comunicação motriz acontece nos jogos, a partir dos códigos gestêmicos e praxêmicos.

Segundo Parlebas (2001, p. 238), código gestêmico ou gestema é "classe de atitudes, mímicas, gestos e comportamentos motores postos em prática para transmitir uma pergunta, indicação, ordem tática ou relacional, como simples substituição da palavra". Para Ribas (2014), os gestemas facilitam as ações dos jogadores e fortalecem, principalmente, os processos cooperativos. No voleibol sentado, esse tipo de comunicação é usado nas combinações de jogadas que ocorrem normalmente por meio de gestemas feitos com as mãos, principalmente pelo levantador. Não é comum evidenciar gestemas direcionados aos adversários, ao considerar que é uma forma de comunicação que facilita a leitura, o que deve ser evitado sempre que possível para o adversário.

Já código praxêmico ou praxema é a "conduta motriz de um jogador interpretada como um signo, cujo significante é o comportamento observável e cujo significado é o projeto tático correspondente a dito comportamento, tal e como é percebido" (PARLEBAS, 2001, p. 349). Ou seja, o praxema consiste da interpretação da conduta motriz de determinado sujeito como algo que significa, que transmite informação, o que acarreta antecipações e decisões motrizes na futura ação motriz de quem a interpreta. Esses processos de codificação e decodificação de mensagens a partir de comportamentos são balizados pelas interações de cooperação e oposição. Ou seja, companheiros irão facilitar essas interpretações entre si enquanto dificultarão ao máximo a leitura e a antecipação do adversário. 
A partir das interações motrizes de cooperação-oposição, os jogadores de voleibol sentado precisam considerar tanto os praxemas opositivos quanto os cooperativos, pois suas decisões motrizes serão baseadas nas informações oriundas da leitura de jogo. No que se refere ao processo de ensino-aprendizagem do voleibol sentado, percebe-se que esses elementos referentes às possibilidades de emissão e interpretação de mensagens são fundamentais para a atuação dos jogadores, ao considerá-los como o elo entre a situação de jogo estabelecida e as decisões tomadas.

Ao perceber a primordialidade, bem como a complexidade, desse processo de leitura e processamento das informações para o sucesso interventivo no voleibol sentado, o professor precisa construir situações didáticas em que os alunos consigam perceber esses elementos, de forma autônoma e dedutiva, entendendo a conexão estabelecida entre as ações e as leituras. A partir dessa empreitada, percebeu-se a necessidade de organizar, sinteticamente, as características evidenciadas pelos modelos dos Universais em relação à lógica interna, bem como os apontamentos para o processo de ensino-aprendizagem, esquematizados no quadro a seguir.

Quadro 1 - Praxiologia Motriz e voleibol sentado: apontamentos para o processo de ensinoaprendizagem

\begin{tabular}{|c|c|c|}
\hline $\begin{array}{l}\text { PRAXIOLOGIA } \\
\text { MOTRIZ }\end{array}$ & \multicolumn{2}{|c|}{ VOLEIBOL SENTADO } \\
\hline Universais & $\begin{array}{c}\text { Características da Lógica } \\
\text { Interna }\end{array}$ & $\begin{array}{c}\text { Apontamentos para o Processo } \\
\text { de Ensino-Aprendizagem }\end{array}$ \\
\hline $\begin{array}{l}\text { COMUNICAÇÃO } \\
\text { MOTRIZ }\end{array}$ & $\begin{array}{l}\text { - Exclusiva e estável. } \\
\text { - Cooperação-oposição } \\
\text { simultânea. }\end{array}$ & $\begin{array}{l}\text { - Facilitar ou dificultar ações e } \\
\text { leituras no contexto do jogo. } \\
\text { - Considerar as interações em } \\
\text { cada momento do jogo. }\end{array}$ \\
\hline $\begin{array}{l}\text { INTERAÇÃO DE } \\
\text { MARCA }\end{array}$ & $\begin{array}{l}\text { - Antagônica. } \\
\text { - Pontuação por } \\
\text { intermédio da oposição. }\end{array}$ & $\begin{array}{l}\text { - Priorizar as formas de } \\
\text { pontuação pela oposição nas } \\
\text { atividades. } \\
\text { - Salientar a relevância da } \\
\text { cooperação para condicionar a } \\
\text { oposição. }\end{array}$ \\
\hline $\begin{array}{l}\text { SISTEMA DE } \\
\text { PONTUAÇÃO }\end{array}$ & $\begin{array}{l}\text { - Sistema de Pontuação } \\
\text { Limite. } \\
\text { - Sem controle temporal. }\end{array}$ & $\begin{array}{l}\text { - Valorar mais pontos aos } \\
\text { comportamentos motores } \\
\text { objetivados no processo. }\end{array}$ \\
\hline $\begin{array}{l}\text { PAPÉIS E } \\
\text { SUBPAPÉIS }\end{array}$ & $\begin{array}{l}\text { - Atacante. } \\
\text { - Defensor. } \\
\text { - Sacador. }\end{array}$ & $\begin{array}{l}\text { - Proporcionar a experiência em } \\
\text { diferentes papéis. } \\
\text { - Apontar a diferença entre papel } \\
\text { e função na organização } \\
\text { estratégica. }\end{array}$ \\
\hline $\begin{array}{l}\text { GESTEMAS E } \\
\text { PRAXEMAS }\end{array}$ & $\begin{array}{l}\text { - Emissões de mensagens } \\
\text { constantes. } \\
\text { - Processos de leitura e } \\
\text { tomada de decisão. }\end{array}$ & $\begin{array}{l}\text { - Desenvolver a capacidade } \\
\text { interpretativa em relação ao } \\
\text { comportamento de } \\
\text { companheiros e adversários. }\end{array}$ \\
\hline
\end{tabular}

Fonte: Elaborado pelos autores, 2017. 
A proposta de construção desse quadro se deu no sentido de facilitar a compreensão de conhecimentos evidenciados pelos Universais sobre o voleibol sentado, sintetizando-os a partir da discussão realizada neste estudo. Além disso, propuseram-se apontamentos relevantes para a abordagem desses conhecimentos no processo de ensino-aprendizagem. Contudo, fica a cargo de cada professor/profissional reconhecer a relevância e a aplicabilidade desses elementos para o processo de ensino-aprendizagem que conduz.

\section{Considerações finais}

Esta investigação buscou apontar os elementos relevantes da lógica interna do voleibol sentado para o processo de ensino-aprendizagem, a partir de uma análise praxiológica, tendo como base os Universais, ferramenta da Praxiologia Motriz. A partir dessa compreensão, o processo de ensino-aprendizagem precisa contemplar esses conhecimentos referentes à lógica interna do voleibol sentado. Evidentemente, é necessário considerar as características dos participantes envolvidos no processo, bem como seus objetivos, níveis de desenvolvimento e capacidades em relação ao voleibol sentado. Esses elementos irão condicionar a forma como o professor enfatizará as características da lógica interna do voleibol sentado e suas aplicabilidades nas aulas ou sessões de treinamento, o que dosará o aprofundamento dessas intervenções em cada elemento que foi evidenciado neste estudo.

Contudo, a adoção de um método de ensino que possibilite a inclusão desses conhecimentos no processo de ensino-aprendizagem é de tamanha relevância quanto a inserção dos próprios elementos da lógica interna. Indicam-se os métodos de ensino por meio de jogos, principalmente o Teaching Games for Understanding (BUNKER; THORPE, 1982) e o Método Situacional (GRECO, 1998), como propostas metodológicas que dão conta de inserir e desenvolver esses aspectos referentes à lógica interna do voleibol sentado.

Entende-se que a desejada superação da hegemonia dos modelos de ensino esportivo tecnicistas só será ultrapassada a partir do momento em que se compreenda o esporte por uma nova perspectiva. Esse novo enfoque deve materializar os elementos inerentes à dinâmica do jogo e traduzi-los em estruturas didáticas pedagogicamente relacionadas e construídas para o desenvolvimento da manifestação esportiva, no caso, do voleibol sentado.

\section{Referências}

BIZZOCCHI, C. O voleibol de alto rendimento: da iniciação à competição. Barueri: Manole, 2008.

BORGES, A. C.; OLIVEIRA, L. S.; NETO, A. M.; BATISTA, G. R.; SOUTO, E. C. Desempenho técnico em equipes de voleibol sentado masculino. Journal Health of Sciences, v. 18, n. 1, p. 24-27, 2016.

BUNKER, D.; THORPE, R. A model for the teaching of games. In: secondary schools. Bulletin of Physical Education, Spring, v. 18, n. 1, 1982.

CARVALHO, C. L.; GORLA J. I.; ARAÚJO, P. F. Voleibol sentado: do conhecimento à iniciação da prática. Conexões, v. 11, n. 2, p. 97-126, 2013.

DEMO, P. Metodologia científica em ciências sociais. São Paulo: Atlas; 1995.

FAGUNDES, F. M.; OLIVEIRA, R. V.; RIBAS J. F. M. Saque e recepção: análises praxiológicas sobre suas influências no voleibol. In: CONGRESO ARGENTINO Y $6^{\circ}$ LATINOAMERICANO DE EDUCACIÓN FÍSICA Y CIENCIAS, UNIVERSIDAD 
NACIONAL DE LA PLATA, 11, Argentina, 2015. Anais... Disponível em: http://congresoeducacionfisica.fahce.unlp.edu.ar/publicaciones11ocongreso/Mesa\%2004_Fag undes.pdf/view. Acesso em: 3 jan. 2017.

GALATTI, L. R.; REVERDITO, R. S.; SCAGLIA, A. J.; PAES, R. R.; SEOANE, A. M. Pedagogia do esporte: tensão na ciência e o ensino dos jogos esportivos coletivos. Revista de Educação Física/UEM, v. 25, n. 1, p. 153-162, 1. trim. 2014.

GARGANTA, J. Para uma teoria dos jogos desportivos colectivos. In: GRAÇA, A.; OLIVEIRA, J. (Org.). O ensino dos jogos desportivos. Porto: Universidade do Porto, 1998. v. 3, p. 11-26.

GRECO, P. J. Iniciação esportiva universal: metodologia da iniciação esportiva na escola e no clube. Belo Horizonte: Editora UFMG. v. 2, 1998.

GIL, A. C. Métodos e técnicas de pesquisa social. 6. Ed. São Paulo: Atlas, 2008.

HARAICHI, M. C.; CARDOSO, V. D.; REPPOLD FILHO, A. R.; GAYA, A. C. A. Reflexões sobre a carreira do atleta paraolímpico brasileiro. Ciência \& Saúde Coletiva, n. 21, v. 10, p. 2999-3006, 2016.

HERNÁNDEZ MORENO, J.; RODRÍGUEZ RIBAS, J. P. La Praxiologia Motriz: fundamentos y aplicaciones. Barcelona, Espanha: INDE Publicaciones, 2004.

LAGARDERA, F. O.; LAVEGA, P. B. Introducción a la Praxiología Motriz. Barcelona: Editorial Paidotribo, 2003.

MACEDO C. D.; MESQUITA, I.; SILVA, M. A. Análise das características da recepção e do levantamento no jogo de voleibol sentado de alto nível. Revista Sobama, n. 12, v. 1, 2007, p. 21-25.

MARQUES, R. F. R.; DUARTE, E. GUTIERREZ, G. L.; ALMEIDA, J. J. G.; MIRANDA, T. J. Esporte olímpico e paraolímpico: coincidências, divergências e especificidades numa perspectiva contemporânea. Revista Brasileira de Educação Física e Esporte, São Paulo, v. 23, n. 24, p. 365-77, out./dez. 2009.

MIRON, E. M. Da pedagogia do jogo ao voleibol sentado: possibilidades inclusivas na educação física escolar. 2011. 340f. Tese (Doutorado em Educação Especial) - Centro de Educação e Ciências Humanas, Universidade Federal de São Carlos, São Carlos, São Paulo, 2011.

MIRON, E. M.; COSTA, M. P. R. Voleibol sentado: brincar e jogar na Educação Física escolar. São Carlos, EdUFSCar, 2013.

PARLEBAS, P. Juegos, deporte y sociedad: léxico de Praxiología Motriz. Barcelona, Espanha: Paidotribo, 2001.

RIBAS, J. F. M. (Org.). Praxiologia Motriz e voleibol: elementos para o trabalho pedagógico. Ijuí: UNIJUÍ, 2014.

SALVADOR, A. D. Métodos e técnicas de pesquisa bibliográfica. Porto Alegre: Sulina, 1986. 
WORLD PARAVOLLEY. Oficcial Sitting Volleyball Rules 2017-2020. 2017. Disponível em: <http://www.worldparavolley.org/wp-content/uploads/2017/06/2017-2020-SITTINGVolleyball-Rules-with-Diagrams.pdf $>$. Acesso em: 1 mar. 2018.

Recebido em: 14/08/2017

Revisado em: 21/02/2018

Aprovado em: 16/05/2018

Endereço para correspondência:

felipemfagundes@live.com

Felipe Menezes Fagundes

Universidade Federal de Santa Maria

Centro de Educação Física e Desportos, Departamento de Desportos Coletivos.

Av. Roraima

Cidade Universitária

97119-000 - Santa Maria, RS - Brasi 